\title{
La experiencia de lo divino \\ EI Emblema XIV de Jesus en de Ziel (1678) como caso de estudio
}

Mauricio Oviedo Salazar

Rijksuniversiteit Groningen

The Experience of the Divine. Jesus en de Ziel's Emblem XIV (1678) as a Case of Study

Recepción: 30 de enero de 2021

Aceptación: 3 de junio de 2021 


\section{Resumen}

El presente artículo expone la imagen religiosa como una herramienta de acceso a la experiencia de lo divino, y muestra cuáles son los elementos que conllevan a conceptualizarla de esta forma. Para ello se utiliza como caso de estudio el Emblema XIV de Jesus en de Ziel, libro protestante de emblemas publicado en 1678, cuyo autor es Jan Luyken. A través de este emblema se puede exponer un claro ejemplo de las formas en que la imagen religiosa cumple su papel mediador y modelador, en cuanto a lo que los usuarios del texto y la imagen comprendían como divino o Dios. La emblemática es utilizada como punto de partida para pensar en las estrategias de comunicación que los medios utilizan para formar parte de la parafernalia religiosa del creyente, para constituirse como herramientas que éste decide tener a su disposición a la hora de configurar tanto la manera en que lo divino forma parte de su vida, como la manera en que su día a día debe ser experimentado para alcanzar lo divino. Así, el artículo posiciona el uso del emblema en el campo de los estudios religiosos como una de las herramientas que moldean — de acuerdo con la concepción de imagen religiosa que se expone— la vida espiritual del individuo.

\section{Palabras clave}

Emblemas, Jan Luyken, imagen religiosa, iconografía del corazón, peregrinaje

\section{Abstract}

The article exposes the religious image as a tool to access the experience of the divine, and shows which elements lead to conceptualize it in this way. The Emblem XIV of Jesus en de Ziel, a Protestant emblem book published in 1678 and authored by Jan Luyken, is used as a case study for this purpose. This emblem constitutes an example of the ways in which the religious image fulfils its mediating and moulding role, in terms of the understanding that users of the text and image had of the divine or God. The emblem is used as a starting point to think about media communication strategies 
used as part of the religious paraphernalia of believers, to constitute themselves as tools believers decide to use when it comes to configuring both the way in which the divine is going to form part their lives, and the way in which their daily life should be experienced in order to reach the divine. In this way the article places the use of the emblem in the field of religious studies as one of the tools that shape -according to the concept of the religious image exposed - the spiritual life of the individual.

\section{Keywords}

Emblems, Jan Luyken, religious image, heart iconography, pilgrimage 
EN EL PRESENTE ARTÍCULO PROPONGO DEFINIR LA IMAGEN RELIGIOSA COMO UNA HERRAmienta de acceso a la experiencia de lo divino, y expongo cuáles son los elementos que conllevan a conceptualizarla bajo esta idea utilitaria, es decir: entender la imagen religiosa como una herramienta, y cuáles son las implicaciones de lo anterior para el usuario de ésta, para la imagen y para lo divino. Especialmente me concentraré en qué nos pueden decir los mecanismos internos que componen la imagen y el objeto que la porta, respecto de esta noción instrumental de mediación o comunicación con Dios. Para esto utilizo como caso de estudio un grabado que forma parte de un libro protestante de emblemas, publicado en 1678 en Ámsterdam, llamado Jesus en de Ziel: Een Geestelycke Spiegel voor 't Gemoed, ${ }^{1}$ cuya autoría, tanto respecto de los grabados como del contenido textual, es del prolífico poeta y artista holandés Jan Luyken (fig. 1). ${ }^{2}$ De manera puntual, me enfoco en el motivo visual del corazón utilizado por Luyken en este grabado, el cual forma parte del Emblema XIV del libro. A partir del mismo, analizo el sistema visual al que perteneció, y considero tanto el grabado del que es parte, como el emblema, la sección de libro y el libro mismo.

A través del Emblema XIV de Jesus en de Ziel, podremos exponer un claro ejemplo de las formas en que la imagen religiosa cumple su papel mediador (de acceso) y modelador, en cuanto a lo que los usuarios del texto y la imagen comprendían por lo divino, o en todo caso, por Dios. Ahora bien, en este caso no me enfocaré en el contexto histórico ni en los usuarios que utilizaron el emblema, sino en el emblema mismo, en sus mecanismos internos y en lo que pretendía provocar a quien consultara el libro. Las claras modificaciones o posibilidades sobre lo que el emblema podría significar, o la forma en que éste podría ser utilizado, dependiendo del contexto y el usuario que lo utilice, es un tema complementario a este estudio, y será trabajado más a fondo en una futura publicación. El enfoque en la emblemática es, por lo tanto, un ejemplo en particular, pero que da pie a pensar en las estrategias de comunicación, en cuanto a composición e impresión que el medio utiliza para alcanzar un objetivo común: formar parte de la

\footnotetext{
1 Jesús y el alma. Un espejo espiritual para el ser interior.
}

2 Sobre Luyken, cfr. Veld, Jan Luyken... 


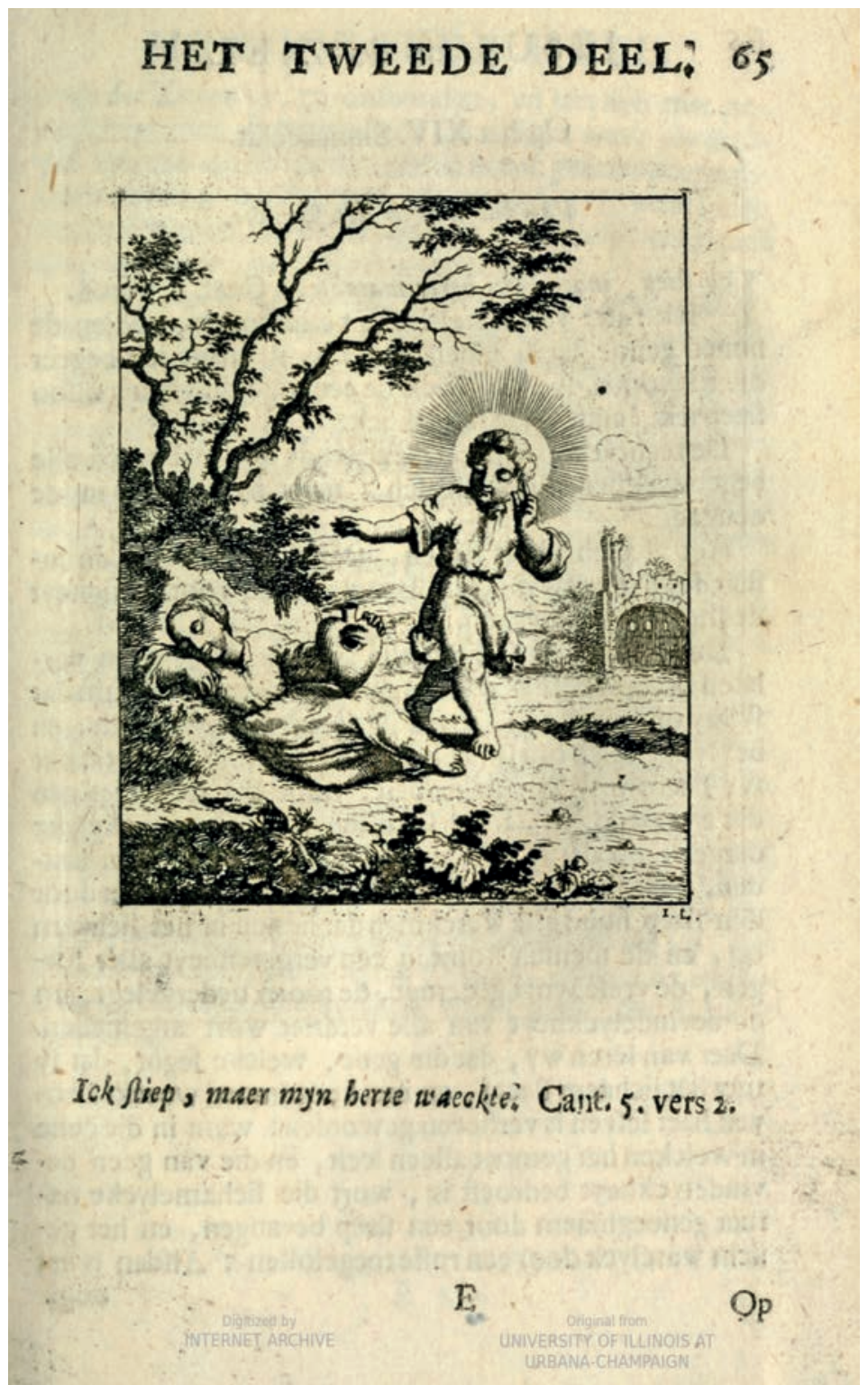

Figura 1. Jan Luyken, Grabado del Emblema XIV de Jesus en de Ziel: Een Geestelycke Spiegel voor 't Gemoed, 1696 [1678], ${ }^{3}$ grabado, Universidad de Illinois en Urbana-Champaign. Imagen obtenida de Hathi Trust Digital Library. Imagen de dominio público. Disponible en https://babel.hathitrust.org/cgi/pt?id=uiuo.ark:/13960/ t1 kh16q8n\&view=1up\&seq=67\&skin=2021.

${ }^{3}$ Las imágenes de Jesus en de Ziel que serán utilizadas provienen de su edición impresa de 1696. Esto no representa un problema, ya que entre 1678 y 1696 los emblemas aquí analizados no sufrieron variaciones. 
parafernalia religiosa, o de las "tecnologías de salvación"4 del creyente; en otras palabras, de las herramientas que el creyente decide tener a su disposición para configurar tanto la manera en que lo divino formará parte de su vida, como el modo en que su día a día debe ser experimentado para alcanzar lo divino, es decir, la salvación. En este sentido, lo que busco es posicionar el uso del emblema en el campo de los estudios religiosos como una de las herramientas que moldean, de acuerdo a la concepción de imagen religiosa que expondré, la vida espiritual del individuo.

El artículo trata primero la definición de imagen religiosa. Seguidamente se realiza el análisis del libro y del Emblema XIV en dos partes; primero se hace una breve descripción de los contenidos del libro y una explicación detallada del Emblema XIV, posteriormente se analizan los mecanismos internos que componen el emblema y el papel que juega el motivo visual del corazón. El artículo termina con una reflexión en cuanto a la función del emblema y sus implicaciones dentro de la noción de imagen religiosa establecida inicialmente.

\section{La imagen religiosa como herramienta de acceso}

El argumento principal a la hora de definir la imagen religiosa es que, si bien no podemos conocer el papel específico que una imagen tiene en la experiencia religiosa de un individuo concreto, sí podemos preguntarnos qué es lo que la imagen ofrece a dicha experiencia. No es la intención de este artículo explicar lo que una experiencia religiosa fue o es, sino en realidad buscar formas en que podemos acercarnos a dichas experiencias para comprender un poco más sobre las mismas en un contexto histórico específico. Es posible crear una definición de imagen religiosa que no intenta forzar una percepción reduccionista de las experiencias religiosas pasadas, sino que puede ser una ayuda para acercarse a la naturaleza humana de manufacturar herramientas para el acceso a una noción de lo divino.

4 Sobre el concepto de "tecnologías de salvación", cfr. Decker, The Technology of Salvation...; y Decker, "Practical Devotion...". 
Bajo el supuesto de que el usuario es capaz de reconocer lo que la imagen ofrece en conjunción con las condiciones histórico-culturales y convenciones sociales a las que pertenece, podemos entonces aproximarnos a la parte de la experiencia religiosa del individuo que está enraizada en los objetos religiosos que la provocan ( $v$. gr. la imagen religiosa).

En la imagen religiosa, el tema religioso se expone en un medio destinado tanto para aquellos que la manufacturaron como los públicos que la utilizaron para formar parte de una práctica religiosa. Las prácticas religiosas, por naturaleza, tienen varios medios de comunicación a su disposición. Las imágenes son uno de ellos. Un parámetro importante para entender las imágenes dentro de las prácticas que realiza el individuo en su entorno religioso, son los trabajos relativos a religión material que ha realizado Birgit Meyer. De acuerdo con Meyer, los medios de comunicación son los aspectos materiales de la práctica religiosa, y sus funciones son literalmente el mediar o, en otras palabras, el formar parte de las prácticas de mediación religiosa. Esto significa que los medios son cruciales para establecer comunicación entre el individuo y lo divino, aquello que el individuo no puede normalmente ver o que le es invisible. ${ }^{5}$ Los medios son, al fin y al cabo, herramientas para acceder a la experiencia numinosa o de lo divino.

En su famoso ensayo sobre el Coloso en la Antigua Grecia, Jean-Pierre Vernant hace una interesante reflexión sobre qué es un signo religioso, la cual puede ayudar a entender la relevancia del aspecto material de la religión, o la noción de la materialidad como portadora de signos religiosos y, por lo tanto, el papel que la imagen religiosa tiene. Un signo religioso no está: "limitado a evocar en la mente de los hombres el poder sagrado al que se refiere. Su intención también es siempre establecer un verdadero medio de comunicación con este poder e introducir realmente su presencia en el mundo". ${ }^{6}$

\footnotetext{
${ }^{5}$ Meyer, "Picturing the Invisible...", 337.

6 "Limited to evoking in men's minds the sacred power to which it refers. Its intention is always also to establish a true means of communication with this power and to really introduce its presence into the human world." [Traducción del autor.] Vernant, Myth and Thought..., 314-315.
} 
Cualquier objeto portador de signos religiosos, orientado a una práctica religiosa, podría implicar no sólo la comunicación con lo divino, sino también una vía por la cual lo divino ocupa un espacio físico en nuestra realidad. La herramienta no sólo permite acceder, sino que también moldea a lo que accedemos. Lo divino no está necesariamente en el objeto, pero el objeto y su uso indican, de una manera u otra, interacción, presencia o, al menos, reconocimiento entre lo divino y humano. Lo divino parece ser sólo entendido, enfrentado o abordado a través de cosas y actos. Lo divino es sólo a través de nosotros o de lo que nosotros hacemos con ello. Hay una mediación que persuade y da la posibilidad de al menos estar cerca de aquello que sea lo divino. Los medios de comunicación no son, entonces, una opción más, sino una parte fundamental de la religión.

Este énfasis que doy al objeto y la imagen religiosa para comprender lo divino y lo religioso está en deuda con las propuestas relativas al estudio de Robert Orsi. Para Orsi la religión trata sobre la relación constante establecida entre entidades suprahumanas y la humanidad, lo que éstas nos hacen y lo que nosotros le hacemos a ellas. ${ }^{7}$ Dicha interacción implica presencia: tanto seres humanos como las divinidades se hacen presentes para poder establecer una relación. La religión es entonces:

la práctica de hacer visible lo invisible, de concretar el orden del Universo, la naturaleza de la vida humana y su destino, y las diversas dimensiones y posibilidades de la propia interioridad humana, tal como se entienden en diversas culturas y en diferentes épocas, para hacerlas visibles y tangibles, presentes a los sentidos en las circunstancias de la vida cotidiana. ${ }^{8}$

7 Orsi, History and Presence, 4.

8 "The practice of making the invisible visible, of concretizing the order of the universe, the nature of human life and its destiny, and the various dimensions and possibilities of human interiority itself, as these are understood in various cultures at different times, in order to render them visible and tangible, present to the senses in the circumstances of everyday life." [Traducción del autor.] Orsi, Between Heaven and Earth, 73. 
Por mucho que se hable de lo divino como transcendente, su presencia se siente, se invoca y se atribuye al curso de la vida humana. La religiosidad y la creencia en la interacción con lo divino implican que tales entidades suprahumanas estén íntimamente vinculadas y comprometidas con la humanidad en niveles sociales, culturales, políticos y económicos. El enfoque a las imágenes religiosas como herramientas pretende en este sentido discutir cómo tratamos con lo divino, donde lo que se quiere es declarar que las herramientas generan para el creyente, un lugar, una ubicación de lo divino, un espacio que es el espacio "religioso" para la arista "religiosa" de la vida del individuo. ${ }^{9}$

Las herramientas para el acceso son por naturaleza inadecuadas y esto es, de hecho, una condición necesaria para que formen parte de una práctica religiosa. ¿A qué me refiero con inadecuadas? Siguiendo a Vernant, podemos decir que es cierto que los signos religiosos comunican y proveen presencia pero, por su naturaleza, los mismos dejan claro que hay un puente, una distancia entre nosotros y lo divino, "entre este poder sagrado y cualquier cosa que intente manifestarlo, forzosamente de manera inadecuada, a los ojos de los hombres". ${ }^{10}$ Esto se puede entender de distintas formas: por un lado, si se entienden como productos del homo faber, el origen humano de los signos religiosos los hace limitados, imperfectos, incapaces de proporcionar el acceso completo a Dios; por el otro, independientemente de si se entienden dichos signos como hechos por el ser humano o no, es la inefabilidad de lo divino lo que provoca que sean inadecuados. Lo que hacemos, por lo tanto, es suplir tantas vías como nos es posible para establecer acceso, por lo demás no podemos hacer más que esperar una respuesta.

Los medios de comunicación son los únicos elementos que dan orientación a cualquier noción de Dios que el creyente posea. Los objetos, las imágenes, los cuerpos, los gestos, sonidos y espacios no sólo son herramientas

9 Orsi, History and Presence, 68

10 "Between this sacred power and anything that attempts to manifest it, perforce inadequately, to the eyes of men." [Traducción del autor.] Vernant, Myth and Thought..., 314-315. 
para enviar un mensaje, sino para modelarlo de una forma en particular. Con la ayuda del usuario, estas herramientas son capaces de formar lo que lo divino devendrá para el individuo y para la comunidad de la que forma parte. ${ }^{11}$

Dado que abordaré un objeto e imagen religiosa, en este artículo me interesa estudiar la imagen en el ámbito donde su función, en cuanto a herramienta religiosa, sólo puede estar presente si es observada. ${ }^{12}$ En un sentido general, más allá de lo religioso, la visión juega un papel clave en nuestro comportamiento respecto al entorno. Observar, además de escuchar, sentir, oler y saborear es fundamental en el proceso a través del cual tenemos conciencia del entorno y de nosotros mismos. Las cosas a las que accedemos por medio de dichos sentidos nos posibilitan asir información, aunque no son información en sí mismas: "El aprendiz tiene que escuchar el discurso para poder captar el mensaje; ver el modelo, la imagen o el texto; manipular el instrumento para extraer la información". ${ }^{13}$ Las imágenes, entonces, como las cosas, son productos diseñados por los que podemos ver y comunicarnos. ${ }^{14}$

Éste también es el caso para la imagen religiosa. Estos procesos tienen implicaciones para la presencia de lo divino. Tal y como se estableció en el párrafo anterior, las imágenes y textos sólo pueden ser proveedores de información sobre una realidad, en nuestro caso: una realidad religiosa. ${ }^{15}$ La imagen es, entonces, un dispositivo que al proveer información provoca, con el tiempo ( $\mathrm{y}$, por lo tanto, a través de la memoria), el reconocimiento de

11 Meyer, "Mediating absence...,", 1036-1037.

12 Debe puntualizarse que uso no es igual a la función o funciones intencionadas. Por función entiendo el objetivo por el cual la imagen fue elaborada en primer lugar: qué era lo que se suponía debía de ser capaz de obrar al ser observada o manipulada (es decir, utilizada).

13 "The learner has to hear the speech in order to pick up the message; to see the model, the picture, or the writing; to manipulate the instrument in order to extract the information." Gibson, The Ecological Approach, 258.

14 Noë, Varieties of Presence, 105.

15 "Una imagen provee alguna de la información de lo que representa, pero eso no implica que está en una correspondencia proyectiva con aquello que representa." Gibson, The Ecological Approach..., 279. 
patrones de un conjunto de elementos de talante religioso relativos a dicha realidad, los cuales sirven para enfocar o restringir, limitar o redirigir la experiencia del individuo con respecto de lo divino.

\section{Jesus en de Ziel y el Emblema XIV}

Con la explicación del concepto de imagen religiosa como herramienta de acceso a la experiencia de lo divino, ahora podemos analizar cómo dicho concepto se formula en un objeto religioso: ¿De qué manera el grabado que nos ocupa provee información respecto de lo divino y cuáles son los puntos principales que, cuando un usuario interactúa con la imagen, contribuyen con la experiencia de lo divino? Para responder a estas preguntas debemos tener claro, en primera instancia, la composición del libro y los contenidos del mismo, ya que la interacción con el grabado seleccionado sucede en el momento que un usuario se relaciona con el objeto que lo contiene. Me refiero a que es importante señalar Jesus en de Ziel, en cuanto objeto religioso, como una herramienta de acceso que a su vez posee diversos dispositivos para interactuar con lo divino, las cuales se complementan, dialogan entre sí y pueden actuar, aun siendo utilizadas como parte del objeto, de manera independiente.

Predominantemente protestante, inclinada en gran medida al calvinismo, la así llamada República Holandesa ofrecía una mayor tolerancia (con sus limitantes, claro está) ${ }^{16}$ a la diversidad religiosa. En este sentido la ciudad comercial de Ámsterdam se convirtió en un centro fértil para diversos grupos religiosos, entre ellos las minorías protestantes como los menonitas, los remonstrantes y los pietistas. ${ }^{17}$ La imprenta se convirtió en uno de los medios más utilizados para comunicar ideas, entre las que se encontraban, por supuesto, las religiosas. Aquí entran en juego los libros de emble-

\footnotetext{
16 Sobre la tolerancia religiosa en los Países Bajos, cfr. Po-Chia Hsia y Van Nierop, Calvinism and Religious Toleration....

17 Sobre minorías protestantes, cfr. Den Hollander, Van Veen, Voolstra y Noord, Religious Minorities...
} 
mas, tanto seculares como religiosos. En el caso de estos últimos, los escritores, artistas y editores idearon un tipo de literatura e imágenes capaces de librar las fronteras entre los diferentes grupos religiosos, en el sentido de que sus libros fueron consumidos por las distintas denominaciones cristianas, incluyendo a los católicos. Entre los autores más famosos de este tipo de libros se encuentra, precisamente, Jan Luyken. ${ }^{18}$

En 1678 el editor Pieter Arentsz publicó la primera edición de Jesus en de Ziel, de Jan Luyken, uno de los artistas más prolíficos en la República Holandesa. En total, Jesus en de Ziel tuvo diez ediciones, desde finales del siglo XVII hasta finales del XVIII. ${ }^{19}$ El libro fue una publicación crucial para la entrada del motivo clásico de Eros y Antero ${ }^{20}$ en los emblemas de amor religioso producidos en la República Holandesa. ${ }^{21}$ Como Barbara Lewalski señala, las figuras de Eros y Anteros fueron reubicadas como alegorías de un peregrinaje espiritual del Amor Celestial y el Amor Terrenal, el Amor Divino y Anima y, por supuesto, de Jesús y el Alma. ${ }^{22}$ Lewalski describe sucintamente este viaje como "el progreso del alma en ruta a la salvación de acuerdo a las tres etapas tradicionales de la vía mística-purgativa, iluminativa, unitiva". ${ }^{23}$

\footnotetext{
18 Sobre libros de emblemas religiosos en la República Holandesa, cfr. Dietz, Literaire levensaders...; Stronks, Negotiating Differences; Lewalski, Protestant Poetics...; Porteman y Smits-Veldt, Een nieuw vaderland voor de muzen. Para conocer más sobre la producción de libros en la República Holandesa y el desarrollo de la imprenta, cfr. Der Weduwen y Pettegree, The Bookshop of the World; Der Weduwen y Pettegree, The Dutch Republic...

19 Jesus en de Ziel tuvo diez ediciones (1678, 1685, 1687, 1689, 1692, 1696, 1704, 1714, 1722 y 1729) y tres reimpresiones (1680, 1744 y 1771).

20 Sobre Eros y Anteros, cfr. Panofsky, Studies in Iconology.

${ }^{21}$ Los jesuitas, especialmente, hicieron uso de Eros y Anteros en contextos religiosos, de manera que su amor y viaje pudieran reflejar aspectos importantes de la vida espiritual. Un buen ejemplo es Typus Mundi atribuido a Philippe de Mallery. Lewalski, Protestant Poetics..., 190. Sobre el tema de Amor Divinus y Anima, cfr. Westerweel, "On the European Dimension...". 22 Lewalski, Protestant Poetics..., 190-191.

23 "The progress of the soul en route to salvation according to the traditional three stages of the mystic way - purgative, illuminative, unitive." [Traducción del autor.] Lewalski, Protestant Poetics..., 192.
} 
Luyken utilizó como parte de sus fuentes visuales y textuales libros de emblemas católicos tales como Amorum Emblemata (1608) y Amoris Divini Emblemata (1608) de Otto van Veen; Pia Desideria (1624) de Herman Hugo;24 y Regia via Crucis (1635) y Schola Cordis (1629) de Benedictus van Haeften. ${ }^{25}$ Las obras de Van Veen proporcionaron un claro modelo para construir el texto en torno a la celebración del amor entre Cristo (Amor Divinus) y el Alma, basándose en interpretaciones alegóricas del Cantar de los Cantares. ${ }^{26}$ Por otra parte, Pia Desideria prefigura la estructura básica respecto de la vía mística seguida por Luyken. Finalmente, la importancia de Van Haeften radica en proveer modelos visuales directos para el libro. El Cordis Vigilia del Schola Cordis es el precedente del grabado que Luyken elaboró para el Emblema XIV (fig. 2).

El libro sigue una disposición homogénea de emblemas y texto. La obra se divide en tres partes, cada una compuesta por trece emblemas. Todo nuevo emblema inicia en la página izquierda, con un poema y un título; debajo del poema aparece una Goddelyk Antwoordt ("respuesta divina") que siempre consiste en un verso bíblico. En la página contigua aparece el grabado del emblema. Estructuralmente hablando, Peter M. Daly ha descrito un emblema, hecho bajo la forma tradicional, como impreso en una sola página y compuesto de una imagen acompañada de dos o más textos breves. ${ }^{27}$ Un emblema está compuesto de inscriptio (lema), pictura (imagen) y subscriptio (epigrama). Las variables de lo que puede ser un inscriptio o subscriptio son tantas como libros de emblemas conocidos en el periodo moderno temprano existen. ${ }^{28}$ La estructura de los emblemas de Luyken no cumple

24 Dietz y Stronks, "German Religious Emblems...", 358. Un posible precedente para Luyken sobre el uso de Pia Desideria en un tono más protestante fue la primera adaptación holandesa de Petrus Serrarius del libro de Hugo en 1653, el Goddelycke aandachten. Stronks, "Dutch Religious Love Emblems", 143. Según Stronks, este libro pasó casi desapercibido.

25 Stronks, "Working the senses...", 690, 692.

${ }^{26}$ Lewalski, Protestant Poetics..., 191.

27 Cfr. Daly, "Emblems".

${ }^{28}$ Lo mismo sucede con respecto a la definición de lo que un libro de emblemas es, al fin y al cabo: "Hasta la fecha, los intentos por definir el género de libros ilustrados llamados libros de emblemas no han tenido mucho éxito. Si las definiciones son demasiado estrechas, excluyen demasiado; si son demasiado amplias, abarcan demasiado". Daly, “Emblems", 1-2. 


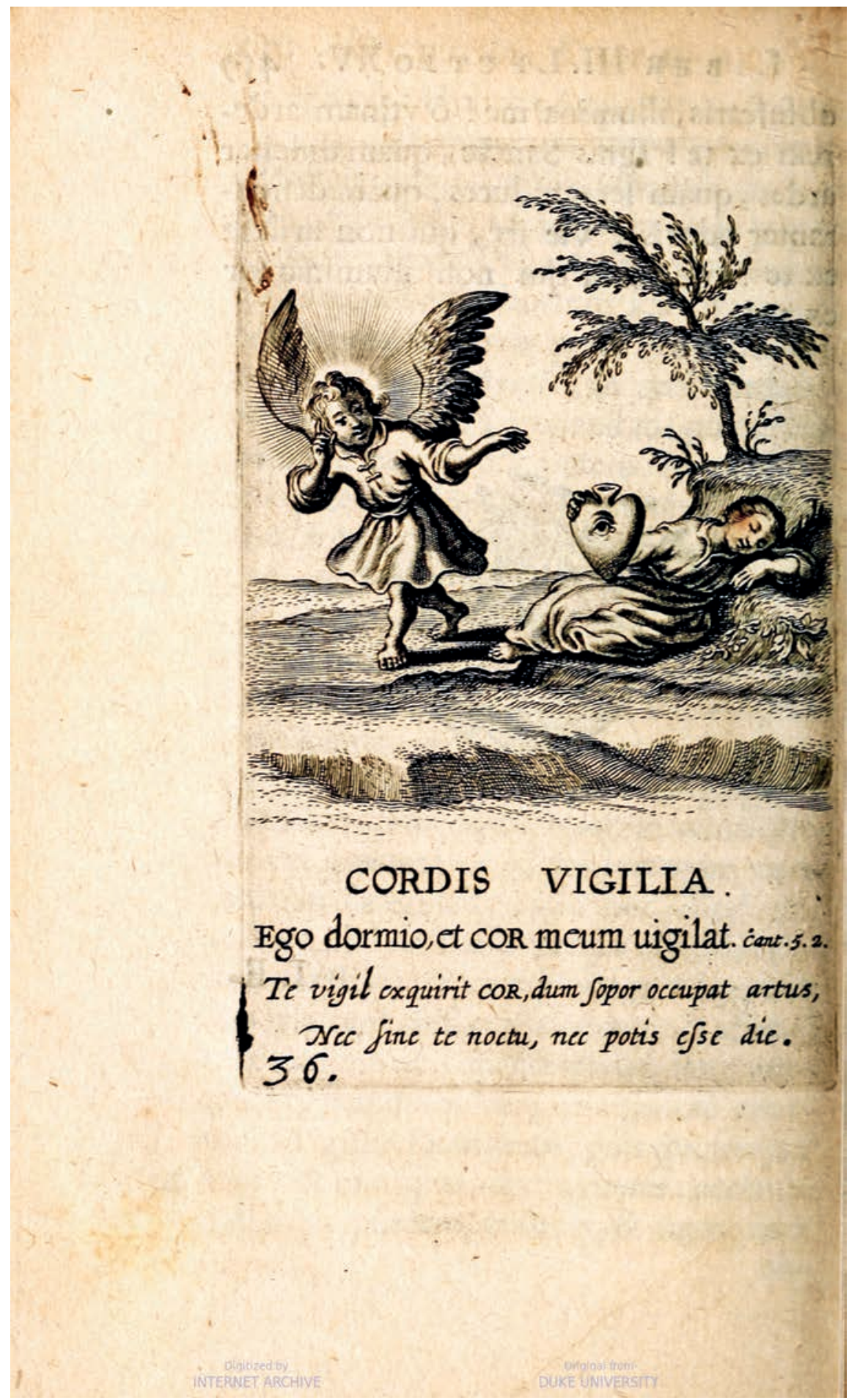

Figura 2. Boetius Adamsz Bolswert, Grabado del Emblema XXXVI de Schola Cordis, 1635 [1629] grabado, Universidad Duke, Durham. Imagen obtenida de Hathi Trust Digital Library. Imagen de dominio público. Disponible en https://babel.hathitrust.org/ cgi/pt?id=dul1. ark:/13960/t0ft9r685\&view=1 up\&seq=498\&skin=2021. 
la estructura estándar propuesta por Daly, ya que consiste sólo de pictura y subscriptio. Como subscriptio, debajo del grabado hay siempre un verso bíblico. Al voltear la página inicia una reflexión más profunda sobre el emblema, con el título Op het $\times$ Sinnebeeldt, ${ }^{29}$ y un subtítulo que refiere al contenido del poema, los versos bíblicos y la imagen. Estas reflexiones toman usualmente dos páginas. En la mayoría de los emblemas, las reflexiones están escritas en prosa, aunque hay algunas excepciones donde se incluyen versos. Una vez que se pasan estas dos páginas, inmediatamente a continuación se presenta el próximo emblema, dispuesto en el mismo orden aquí descrito.

Los emblemas siguen una secuencia narrativa lógica. Se puede trazar una historia a través de ellos por medio de las imágenes, sus poemas acompañantes y posteriores reflexiones. Las imágenes son en la mayoría de los casos claras en su mensaje y en su conexión con los poemas. No hay más de tres figuras por cada imagen, aunque habitualmente sólo son dos. Si se presenta una sola figura ésta suele ser el Alma. En cuanto a la composición no hay variaciones dramáticas en las configuraciones de las imágenes, lo que da una cierta coherencia visual y continuidad a la obra.

En una de las primeras secciones del libro, llamada Kort bericht aan de leser ("mensaje corto al lector"), el lector es informado de la función intencionada de los emblemas. Su papel es múltiple. Algunos han sido puestos

para elevar el Alma fuera del sueño de los Pecados; otros para elevar el Alma en su pena, angustia y tentación; otros para hacerla enamorarse del Origen de toda belleza. Algunos huelen a la querida verdad; algunos al amor, algunos llaman al Alma a unirse con Dios: También aquellos con su noble olor y deleite nos muestran un destello del alegre y abundante Paraíso; un eterno jardín de deleites de Ángeles y Almas Benditas. ${ }^{30}$

\footnotetext{
29 Sobre el emblema "X".

30 "Om de Ziele uyt den slaap der Sonden op te wecken; andere om de Ziele te verquicken in hare verslagenheyt, angst en aanvechtinge; andere om haar op den Oorspronk aller schoon-
} 
Luyken no sólo otorga funciones a los emblemas donde su mediación es clara, como la de "elevar", "hacer enamorar" o "llamar" al Alma del mundo terrenal, de lo verdaderamente bello o hacia la unión con Dios, respectivamente, sino que les da características que apelan a otros sentidos corporales, como olores que remiten a la verdad, al amor, o que provocan revelación al usuario de los mismos. A este mensaje le sigue el Voor-sangh ("preludio" o "canción introductoria"). Aquí Luyken habla directamente al Alma, y nos da un breve resumen de lo que trata el libro. Se refiere al viaje que el Alma debe tomar para regresar a su verdadero hogar; sobre lo que se ha perdido, los placeres y la decepción de las cosas terrenales; sobre el amor que Jesús tiene por nosotros, y de lo que será del Alma una vez que se haya casado para la eternidad con él. ${ }^{31}$

De esta manera, a lo largo de los emblemas que componen el libro, lo que el usuario lee y ve es el viaje del Alma. La primera parte describe visual y textualmente cómo ésta, despertada por el poder de Dios, decide sin vacilaciones y con honestidad dejar el mundo y a sí misma (en tanto que su forma terrenal) para poder llegar a Dios, su hogar por derecho. El Alma comienza el viaje problematizando las tentaciones en las que cae la carne, y la tensión entre la carne y el espíritu. Ella desea un bien superior, reconociendo, a través de Dios, que su vida actual en la Tierra no es su legítima morada sino una prisión, y que necesita ir en busca del lugar al que realmente pertenece. Comienza, asimismo, la búsqueda por la belleza de lo Divino en todas las cosas creadas. Es posible discernir a Dios en la naturaleza, pero tal discernimiento sólo puede ser dado por el mismo Dios. Hay una realidad interna y eterna en todo lo que vemos en el mundo. Ese bello paraíso eterno se manifiesta sólo en el individuo interior, y aunque en el exterior se puede ver la belleza esencial (con los ojos del espíritu), el reino

\footnotetext{
heden te doen velrieven. Sommege ruycken van dierbare waarheyt; Sommege van Liefde, sommege locken de Ziel tot de vereeniging met Godt: Ook synder die met haar edele Reuck en veruw ons vertoonen een weynigjen van 't vreugden ryke Paradys; een ewige lust-gaarde der Engelen en salige Zien." [Traducción del autor.] Luyken, Jesus en de Ziel, A3r.

${ }^{31}$ Luyken, Jesus en de Ziel, A4r-A4v .
} 
terrenal está destinado a perecer. Sin embargo, lo que hay detrás de lo terrenal es la eternidad. ${ }^{32}$

La segunda parte refiere a cómo el Alma, a través del camino del arrepentimiento, ha alcanzado, por la gracia divina de Dios, la vida contemplativa. En este estado el Alma relata una serie de altas y amorosas verdades, cual testimonio para los demás que recorren el mismo camino. El Alma cuenta ahora con conocimiento, ha sido iluminada: su verdadero Ser ha despertado. Sabe, ahora, que el pecado está al acecho y que, incluso si ha recibido la gracia de Dios, su confinamiento en el viejo Adán (la carne) hace de la tentación una constante. Éste es el contexto en el que el Emblema XIV es introducido como primer emblema de la segunda parte. La narración continúa con el argumento según el cual, mientras Cristo permanezca en el corazón, la oscuridad será devorada por la luz y los pecados serán perdonados porque "Wanneer Christus opstaet soo sterft Adam" ("cuando Cristo resucita, Adán muere"). ${ }^{33}$ Luyken repite una idea presente en la sección anterior, relativa a la constante muerte de Adán (la carne). Ante la constancia de la muerte, el Alma nace de nuevo en Cristo. Ella comparte tanto la muerte, la resurrección, y la ascensión, así como el reino eterno de Cristo, ya que el Alma ha nacido de la carne y la sangre de Éste. Nacer de nuevo es tener un nuevo cuerpo espiritual en Dios, el cual está oculto en el cuerpo adámico terrestre. ${ }^{34}$

En la tercera parte, el Alma se enfoca en su deseo más grande, el cual, según su naturaleza en el amor de Cristo, es la unión absoluta con su amado y sumergirse en el todo divino, como una gota de agua en el vino. ${ }^{35} \mathrm{El}$ Alma se resigna por completo ante Dios y expresa su ferviente deseo de unión con su amado. Dios responde que, a través del regalo del nuevo

32 Luyken, Jesus en de Ziel, 9-61.

${ }^{33}$ Luyken, Jesus en de Ziel, 70.

${ }^{34}$ Luyken, Jesus en de Ziel, 63-115.

35 Luyken, Jesus en de Ziel, 117. La idea de una gota de agua en el vino es parte de una larga tradición mística en el cristianismo. Por ejemplo, se puede ver en De Diligendo Deo de Bernard de Clairvaux, o en Rede der underscheidunge de Meister Eckhart. Sobre esta idea, cfr. Lerner, "The Image of Mixed Liquids...". 
nacimiento en su espíritu, el Alma se acerca gradualmente al Paraíso. El Alma comprende ahora la separación estricta entre su naturaleza original y la naturaleza de la carne, el amor divino y el amor mundano, el tesoro divino (que reside en el corazón) y el tesoro mundano (mero placer externo), y así se posiciona contra el mundo. En el emblema final del libro el Alma reafirma su deseo de disolverse en Cristo, en su fuego amoroso, reconociendo los límites de la carne y anhelando el reencuentro con el Señor después de la muerte del "viejo hombre". Finalmente, el Alma alcanza, por fin libre de la carne después de toda su peregrinación, su legítimo hogar en la divina eternidad. ${ }^{36}$

Ahora bien, ¿cómo encaja el Emblema XIV en esta narrativa? El emblema inicia con el poema, cuyo título es De Ziele rustende van alle uyterlijcke menighoudigheden, waeckt met het inwendige ooge des gemoeds (fig. 3). ${ }^{37} \mathrm{EI}$ contenido del poema comienza por aclarar que el "Yo", es decir, "el Alma", no está muerto (aunque le parezca al mundo como si lo estuviera); es sólo la carne la que está durmiendo. El Alma descansa de lo terrenal, de lo mundano y de los deseos animales de la carne; pero mientras descansa, el corazón está atento a Dios y a lo divino, de modo que cuando el Señor la toque no la encuentre dormida o aletargada. El ojo del ser interior está siempre abierto, capaz de ver el bien eterno, la luz y la vida en Dios. Mientras la carne duerme se olvida de lo que no pertenece al corazón, y que debe ser ignorado por el Espíritu. Al seguir tal camino la vida mundana se deja atrás, a favor de una vida correcta que ha sido encontrada gracias a Dios. ${ }^{38}$ Con la conclusión del poema viene la Respuesta Divina, un verso de Mateo 26:41; (“El Alma que descansa de todas las multiplicidades exteriores observa con el ojo interno del ser interior.") ${ }^{39}$

\footnotetext{
${ }^{36}$ Luyken, Jesus en de Ziel, 168.

37 "Waekct ende bidt, op dat ghy niet in versoeckinge en komt."

38 Luyken, Jesus en de Ziel, 64.

${ }^{39}$ Luyken, Jesus en de Ziel, 64. Versión obtenida de Reina Valera Antigua (de ahora en adelante RVA): "Velad y orad, para que no entréis en tentación".
} 


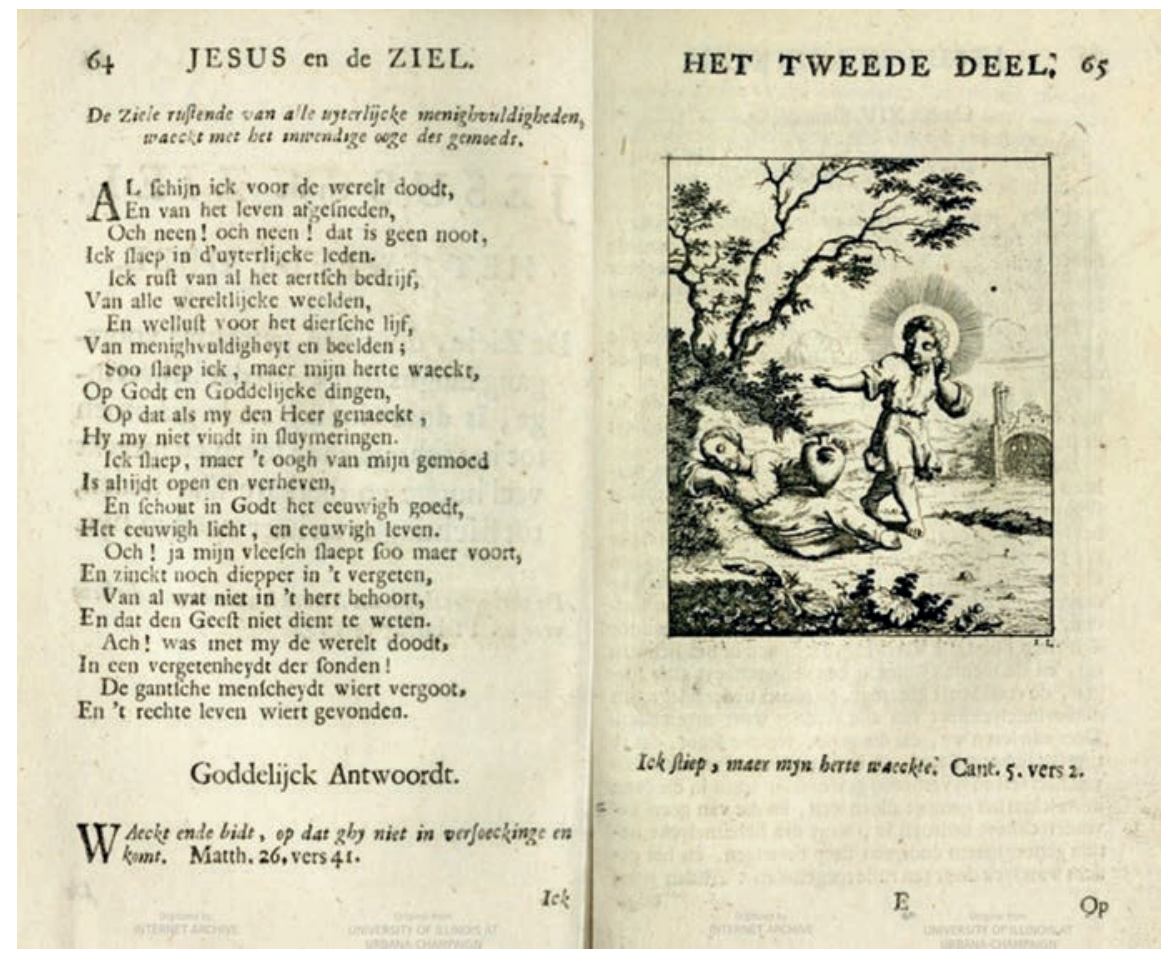

Figura 3. Jan Luyken, pp. 64 y 65 de Jesus en de Ziel: Een Geestelycke Spiegel voor 't Gemoed, 1696 [1978], Universidad de Illinois en Urbana-Champaign. Imagen obtenida de Hathi Trust Digital Library. Imagen de dominio público. Disponible en https://babel. hathitrust.org/cgi/pt?id=uiuo.ark:/13960/t1kh16q8n\&view=1up\&seq=67\&skin=2021.

Le sigue entonces la imagen impresa en la página contigua. La imagen está compuesta por un niño en pie, con un nimbo alrededor de su cabeza, y gira la cabeza hacia la derecha, con el brazo izquierdo flexionado dirigido a su cara. La mano izquierda parece apuntar con el índice ya sea a la cabeza o hacia arriba. Su brazo derecho tiene la palma abierta hacia abajo. El niño tiene sus ojos bien cerrados o bien mirando hacia abajo, en dirección a la otra figura. Porta una simple túnica, atada a la cintura con una faja. El niño parece estar en el acto de encontrar la otra figura de la imagen: una mujer joven o niña que yace en un montículo con la cabeza recostada en el brazo derecho y con los ojos cerrados, aparentemente dormida. Ella también porta una túnica ceñida a la cintura. Su mano izquierda sostiene un corazón localizado justamente debajo de la palma derecha abierta del niño. El corazón tiene un ojo abierto en su centro, que mira directamente al 
receptor de la imagen. Las figuras tienen como fondo un paisaje, con lo que parece ser un ábside en ruinas. La imagen representa al Niño Jesús encontrando el Alma dormida mientras su corazón está vigilante. Debajo de la imagen aparece impreso un verso del Cantar de los Cantares 5:2: "Yo dormía, pero mi corazón velaba". ${ }^{40}$

El texto en prosa que sigue al pasar la página lleva el título Op het XIV. Sinnebeeldt y el subtítulo Van het waken des Geestes ("Sobre la vigilia del Espíritu", fig. 4). Éste es una continuación del tema dado por el poema, los versos bíblicos y la imagen. Inicia con una descripción del reposo de lo mundano y el deseo de lo que está por venir, de tal manera que el Alma duerme mientras el corazón vigila: "La carne debe dormir, la fe debe vigilar: los deseos del cuerpo deben dormir, la prudencia del corazón debe ser vigilante." ${ }^{\prime 1}$ En la reflexión que sigue, Luyken presenta a los santos como modelos, y establece que no duermen por pereza, sino porque la carne lo exige. Duermen de lo que es transitorio, y con su verdadero ser observan lo eterno. El sueño, indica Luyken basándose en una larga tradición, es lo más cercano a la muerte, a la muerte del cuerpo mortal; la vigilia del corazón es lo más cercano a nuestro verdadero cuerpo o ser, libre de la carne. El Alma, despierta y vigilante, es conducida por lo divino a su ser más elevado justo ante la recámara del Rey Eterno. El Alma exaltada, abrazando su más íntimo ser, llega a sentir en esta amorosa fuerza una corriente que viene del Espíritu Santo, como una fuente viva que vierte dulzura eterna. Al estar tan arriba en la luz, tiene todos sus sentidos anulados, y el simple ojo se abre en el reino de la fuerza amorosa. Este ojo, contemplando con claridad espiritual, ve todo lo que Dios Es. Pero cuando el Alma vuelve a sí, se percata de que esta experiencia es imposible de expresar con palabras, y no es fácil de comprender o, en todo caso, confesar. ${ }^{42}$

Si consideramos lo dicho y visto tanto en el poema como en la imagen, en adición a los versos bíblicos y la reflexión descrita, las funciones que el

\footnotetext{
40 “Ick sliep, maer myn herte waeckte." [Traducción de RVA.] Luyken, Jesus en de Ziel, 65.

41 "Het vleesch moet slapen het geloven waken: de lusten des lichaems moeten slapen, en de voorsichtigheyt des herten moet waken." [Traducción del autor.] Luyken, Jesus en de Ziel, 66.

42 Luyken, Jesus en de Ziel, 66-67.
} 
66 JESUS en de ZIEL.

Op het XIV. Sinncbecldt.

Van bet waken des Geeffes.

Ick flaep, macr myn berre traecke. Cant. 5. vers 2. I ick rufte van wereltlycke verluftingen, nadien de finnen genoegfaemu ingeflapen zyn ; maer ick begeer fliep ick, cude alfoo waeck ick.

De rechtveerdize flaept, aengaende het quade, en alle bercerlyckheden des vieefen; maer hy wa dcugden.

Het vleefeh moet flapen, het gelove waken : de lufen des lichaems moeten flapen, en de voorfichtigheyt des herten moet waken.

De Heyligen verachten alle sertiche dingen, en verlaten het gewoel des werelts gantích en gaer, niet om dat fy luy of traegh zyn, maer fy wercken inwendigh, en bevlytigen fich om in het herte aen te fchouwen, wat dat fy, dacrom fy zgn gefechapen, want fy flapen niet om dat fy moede zyn, maer fy ruften van de verganckelyke dingen, op dat fy tevryer de ceuwighe betrachten fouden. De flaep is een evenbeeldt des doodts, wantdoor den flaep houd alle werckingh der finnen in het lichacm op, en de inenfeh komt in een vergetenheyt aller forgen, devrefe wort gedempt, de toorn nedergelegt, en de bevindelyckheyt van alle verdriet wort aficeneden. Daet van leren wy, dat die gene, welcke feght, dat fy met het lichaem flacpt, en met het gemoed waeckt, boven haer felven is verheven geworden: want in die gene in welcken het gemoet alleen leeft, en dic van geen bevindelyckheyt bedroeft is, wort die lichamelyeke natwer genoeghfaem door een laep bevangen, en het ge-

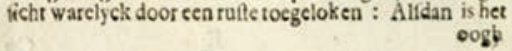

HET TWEEDE DEEL. 6.7 ooghder Zielen vry en ontbonden, en laet fich met onderfcheytzien. Schout alleen die dingen aen, die hooger zyn dan de fichtbare: alfdan in het gehoor genoeghfiem doodt en afgeftorven, als het gene zyn werckinge verlooren heeft. Maer het gemoet houd fich befigh met dingen, die het vernuft ver overtreffen.

De krachten daer de Ziel mede werckt, zyn recht als Camenieren, die haer leyden indat hooghte haers felfs, voor de flaepkamer hacrs ceuwigen Koning hs. Ende als deZiele met haer krachten op verheven is, in 't hoozfte boven alle gefehapen dingen, ende vriendelyck van haer beminde wort omhellt, foo moeten de krachten wycken en ruften van alle werckelykheden, en de Zicic wort doorvloeyt van den Geeft Godts, en de filigheydt gewercks in meniger, de dan gevoelt $z y$ in de liefhebbende kracht een treck des Heyligen Geeftes; als een levendige fonteyn, die ves Als Z revierender ecuwiger foctigheyt.

ticte too hoogh in het licht komt, dat het verftandt verblindt wort, gelyck dat ooge van deklactheyt der Sonnc, 10o ontranght fy boven de verittandelycke kracht een fimpel ooge, open geloken in de wercklykheydt der liefheboenece kracht; welck ooge, met een timpel aenichouwen in die geeltelycke klacrheyt, fict al wat Godt is cenvuldighlyck. Maer wat den geeft des menfchendan gebeurt, en wat hy bekent op die tyt, dat en is niet met woorden uyt te fpreken, nochte hy en bekent dat felve niet volkomen, als hy weder tot fich felreakomt.

Figura 4. Jan Luyken, pp. 66 y 67 de Jesus en de Ziel: Een Geestelycke Spiegel voor 't Gemoed, 1696 [1678], Universidad de Illinois en Urbana-Champaign. Imagen obtenida de Hathi Trust Digital Library. Imagen de dominio público.

Emblema posee son: 1) hacer saber a los usuarios que deben estar siempre atentos a la presencia y llamada de Dios; 2) que su verdadero ser reside en lo interno del corazón y, que por ello, este órgano vital es el sitio donde Cristo reside o es capaz de residir; y 3) dejar claro que es sólo a través de la apertura de este "ojo espiritual del corazón", comandado por lo divino, que el usuario es capaz, mientras esté en la Tierra, de experimentar y ver a Dios; de experimentar y ver la esencia divina que hay detrás de la naturaleza y en las actividades cotidianas de la vida, hasta la muerte. Es a través de los "ojos del corazón" que el creyente no sólo debe ver sino también comportarse. Siempre vigilante, con el verdadero ser atento a la presencia de Dios en su vida y en su fuero interno. 
Estas funciones se pusieron a disposición de los usuarios del libro a través de una serie de estrategias de composición y de comunicación empleadas por sus creadores, entre ellos Luyken. Éstos son los mecanismos internos que rodean al motivo visual del corazón, lo insertan dentro de la escena compuesta en la imagen y son parte de lo que el objeto en general ofrece religiosamente. El motivo es parte de una red de vínculos e interacciones materiales y visuales, en este caso una imagen, una página, un folio y un libro. Al definir los mecanismos internos del primer emblema donde el corazón aparece, intentaré explicar qué estrategias visuales y cognitivas se utilizaron en la creación del objeto para procurar la experiencia religiosa, la mediación con lo divino, la presencia de Dios a través del emblema.

\section{Mecanismos internos: formas visuales y textuales de representación en el Emblema XIV como herramienta de acceso}

¿A qué me refiero cuando hablo de mecanismos internos? Los objetos y sus contenidos tienen una serie de formas para trabajar o, en otras palabras, se supone que están hechos para trabajar de una cierta manera. Los modos en que sus contenidos se han dispuesto a lo largo del objeto implican diseño, decisiones y funciones. Si tomamos en cuenta la descripción del objeto y con un análisis de cómo funcionan el objeto y sus imágenes, en este caso una en específico, podemos comprender cómo era que el objeto estaba propuesto para ser consumido. Esto no significa que al fin y al cabo fuese consumido de esta manera, pero que el objeto ofrece de forma puntual una serie de signos, secuencias y configuraciones que le permite funcionar ya sea de una manera en concreto, o una serie de maneras en específico. Éstos son los mecanismos internos del objeto: la función del objeto de acuerdo con lo que el objeto en sí nos puede proveer al analizarlo, observarlo y manipularlo.

El diseño de un libro permite diversos movimientos e interacciones con el objeto. Si el usuario quiere leer su contenido, tiene que abrirlo y continuamente pasar sus páginas para que éste sea revelado. El consumo de un libro en términos de lectura y, en nuestro caso, observación de imágenes, 
implica entonces una serie de revelaciones, y dichas revelaciones de información dependen de las acciones y habilidades del usuario y su compatibilidad con las condiciones ofrecidas con el libro para su uso y consumo. ${ }^{43}$ Con Jesus en de Ziel lo que es revelado por el usuario conlleva poesía, explicaciones, la Palabra de Dios e imágenes. De ese modo, los emblemas que incluyen el corazón, como lo sería el Emblema XIV, no se dan sin más, sino que se descubren, se desvelan al abrir el libro y al llegar a esas páginas, de cualquier manera que el usuario haya llegado a ellas. Ese camino, todo ese tiempo y proceso para llegar al Emblema XIV, por ejemplo, hace de las configuraciones entre prosa, verso, Biblia e imagen un proceso dinámico constante.

Podemos delinear al menos dos formas básicas de leer lo que sucede en la imagen del Emblema si tomamos en consideración que el usuario en el que estamos interesados es uno que consumiría la imagen como parte de su interacción con el libro. En el primer escenario la imagen se aborda desde el punto de vista de la narración de la obra en su conjunto. Aquí, el lector sigue la historia expuesta por Luyken que he descrito brevemente. Tomemos el Emblema XIV. Si el lector sigue el orden del libro en secuencia, entonces es evidente que el emblema funciona como transición e introducción: es el primero de la segunda parte de la obra, y, por lo tanto, también se relaciona en cierta medida con la conclusión de la primera parte, la cual pertenece al Emblema XIII (fig. 5). En este último vemos al Alma enfrentada, con la ayuda de su amado (Jesús), a una vida pecaminosa, cansada de ver cómo la lujuria en el mundo trata de derrotarla. Esta circunstancia está representada por el Alma y Jesús en una barca en el mar. El poema cuenta cómo los dos tratan de llegar al otro lado, remando contra la corriente de pecados del mundo. La respuesta divina da seguridad en cuanto a la meta: "Mas el que perseverare hasta el fin, éste será salvo" (Mateo 24:13). ${ }^{44}$

\footnotetext{
${ }^{43}$ La idea de revelación como un acto donde el usuario del objeto debe participar es tomado de las propuestas de Bernhard Siegert relativas a las "técnicas culturales". Cfr. Siegert, Cultural Techniques.

44 "Wie volherden sal tot den eynde, die sal salig worden." [Traducción de RVA] Luyken, Jesus en de Ziel, 59.
} 


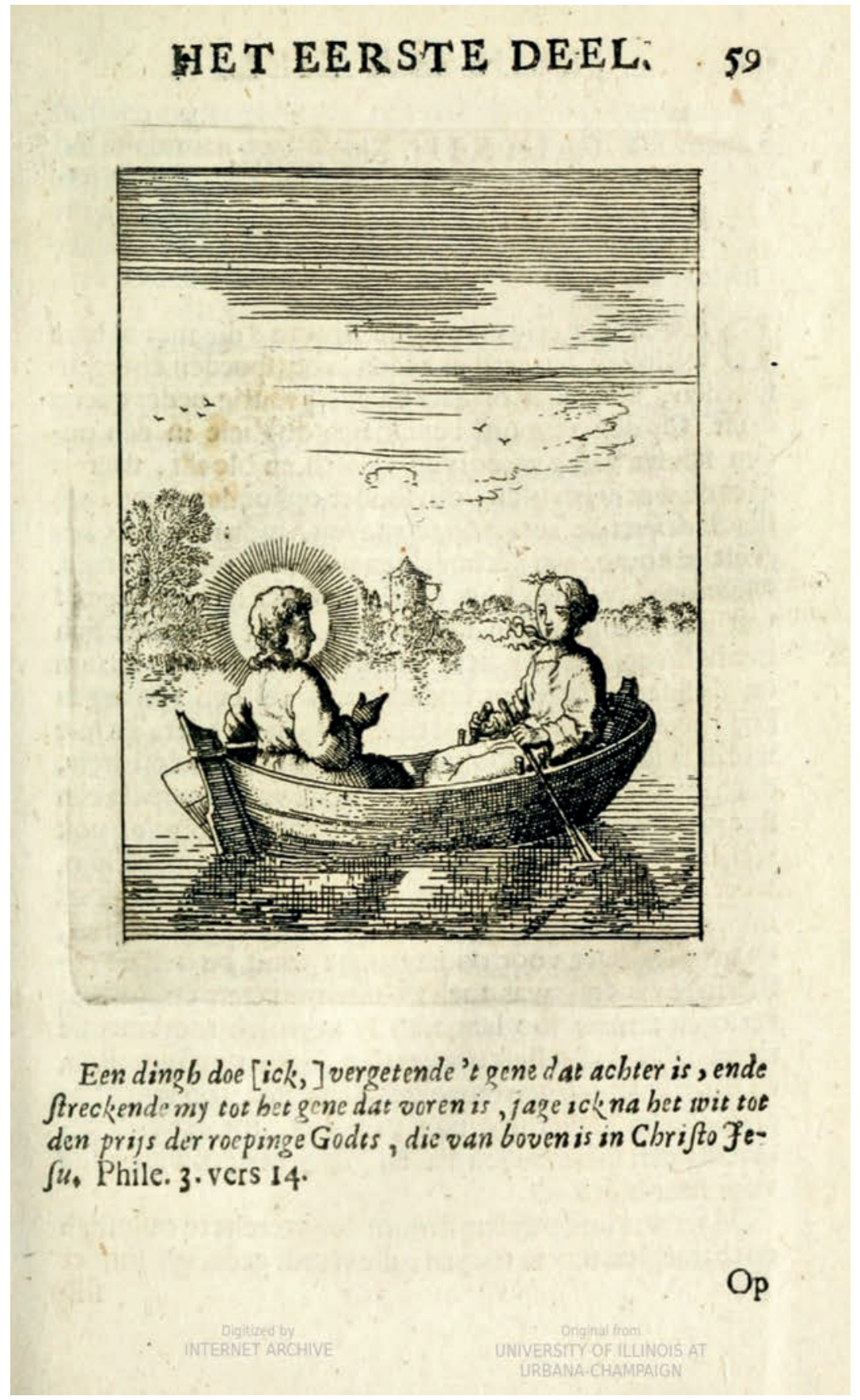

Figura 5. Jan Luyken, Grabado del Emblema XIII de Jesus en de Ziel: Een Geestelycke Spiegel voor 't Gemoed, 1696 [1678], grabado, Universidad de Illinois en UrbanaChampaign. Imagen obtenida de Hathi Trust Digital Library. Imagen de dominio público. Disponible en https://babel.hathitrust.org/cgi/pt?id=uiuo.ark:/13960/t1kh16q8n\&view $=1$ up\&seq $=67 \&$ skin $=2021$ 
Habiendo llegado, ahora, a la apertura de la Parte II, el Alma descansa, con un corazón abierto y vigilante, guiada por Dios. El Alma está, entonces, en las condiciones necesarias para emprender el resto del viaje que se relatará en la segunda parte del libro.

Una segunda forma de leer las imágenes es notar que los emblemas tienen sentido incluso si se leen fuera de secuencia, no como parte de la narrativa. Los emblemas en Jesus en de Ziel pueden ser igualmente entendidos como partes independientes de un todo. Si volvemos a los Emblemas XIII y XIV, podemos observar que el primero puede ser leído solo, como una imagen independiente que describe el viaje contra esta marea mundana, y la llegada a una orilla segura que es en realidad el destino final (el Cielo). En esta lectura, el Emblema XIII deja de ser meramente un evento que termina en la llegada a un lugar para descansar antes de continuar con el viaje, sino que contiene en sí mismo un horizonte más significativo. El emblema XIV, a su vez, leído de forma independiente de la secuencia narrativa, implica que incluso mientras se duerme o se descansa el verdadero "yo" necesita vigilar la presencia de lo divino. En resumen, los emblemas que componen el libro no dependen unos de otros para su significado, pero permiten una lectura secuencial. Luyken diseñó y compiló las imágenes en un orden que recompensa su uso tanto en grupo como independientemente, asegurando así una serie de significados y puntos de cohesión.

Estas dos formas de lecturas evidencian, junto con la descripción relativa a los contenidos del libro, el papel del grabado dentro de un discurso visual y textual en el que lo que se busca es involucrar al usuario como parte de la narración (o de dicho discurso). Jesus en de Ziel no se propone como una historia ajena al usuario, sino que es una representación metafórica de lo que la vida del lector es o debería ser. En otras palabras, el lector debería sentirse identificado con el personaje del Alma en el libro, y los eventos que se narran en cada uno de los emblemas son representaciones visuales y textuales de lo que es el vivir diario, el peregrinaje cotidiano del creyente. En este sentido, los emblemas no se proponen necesariamente, aunque lo pueden ser, como herramientas para la contemplación o reflexión sobre di- 
versas enseñanzas espirituales, sino como un espejo alegórico de la vida del individuo. Parafraseando el subtítulo del libro, es un espejo espiritual en el que, al mirarse el creyente en él, verá reflejada su parte espiritual, su Alma, en potencia de ser divina (aliada a Dios), y vivirá una vida acompañada de su amado Jesús, cuyo final es una vida después de la muerte en unión con él. En otras palabras, Jesus en de Ziel, en cuanto a herramienta de acceso a la experiencia de lo divino, propone una representación visual y textual, ayudada de la palabra de Dios (en las Respuestas Divinas y diversos versos bíblicos) de cómo la vida del creyente es, o mejor dicho, debe ser. Es un objeto, por lo tanto, de introspección para el individuo, donde se indica la vía para alcanzar una forma de ver y entender a Dios, un proceso que involucra el despertar del verdadero ser, para ver, y para experimentar lo esencial detrás de todo aquello creado por Dios.

Esta propuesta de la utilidad del libro para el usuario se sirve de las estrategias textuales y visuales generadas por Luyken y los artífices del objeto. La forma en que está escrito e ilustrado procura que sea sencillo para que el lector se adentre en la narrativa expuesta en el párrafo anterior. ¿Qué nos pueden decir entonces la composición del grabado y de los textos del Emblema XIV sobre esto? Para responder quisiera concentrarme en la forma en que los personajes en el grabado fueron representados, ya que es uno de los elementos más importantes en las tácticas empleadas para que sea efectivo lo que el libro y el emblema ofrecen.

Comienzo con el Alma. Ella no es un retrato de una persona reconocible, representada de forma realista. ${ }^{45}$ En el mejor de los casos, su representación puede describirse como la de una joven, cuyos rasgos faciales son intercambiables con los de muchas otras representaciones femeninas de Luyken. ${ }^{46}$ Su falta de parecido con una persona en específico permite que

45 Sobre la representación del Alma como femenina, cfr. Schorsch, "Emblematic and Allegorical Images...".

${ }^{46}$ Para nombrar algunos ejemplos: el frontispicio para De Zedelyke Werken (1674), de Stephanus Curcellaeus); el de Christelyke Sin - en Geestryke Annotatien (1686), por Mattheus Bois; el de Christelyke godgeleerdheid (1701), para Philippus van Limborch; y finalmente los grabados incluídos en Voncken der liefde Jesu (1687), libro de la autoría de Luyken. 
sea utilizada como vehículo de identificación para cualquier usuario. La reducción de su expresión al mínimo suprime efectivamente cualquier personalidad individual de la figura, a fin de que pueda ser una representación genérica del Alma arrepentida, llena de un anhelo de amar y unirse con Dios. Un perfil tan básico la convierte en el espejo perfecto para los que están en la misma situación. Ella es nadie o, mejor dicho, es todo el mundo, la base común mínima de un cristiano en busca de un renacimiento, de la salvación, y, por lo tanto, de la unificación en el amor a Jesús. Tomando prestados los términos de análisis de Scott McCloud en el campo de los estudios de historietas, ella es una caricatura deliberadamente distante de las representaciones realistas. Ella se convierte, por lo tanto, en: "un vacío en el que nuestra identidad de la conciencia de sí es arrastrada... una cáscara vacía que habitamos y que nos permite viajar a otra realidad. No sólo observamos la caricatura, jnos convertimos en ella!". ${ }^{47}$

Las observaciones de McCloud respecto a las caricaturas, o en cuanto al acto de caricaturar a manera de amplificación a través de simplificación, nos puede servir aquí: "Cuando abstraemos una imagen a través de la caricatura, no estamos necesariamente eliminando detalles, sino enfocándonos en detalles específicos. Al despojar a una imagen de su 'significado' esencial, un artista puede amplificar ese significado de una manera que el arte realista no puede". ${ }^{48}$

La forma "caricaturesca" en que Luyken dibuja el rostro del Alma sirve, entonces, para dar a la figura no más que la identidad del Alma, sin mayores especificidades, y mediante esta estrategia de representación más gente puede sentirse identificada con la imagen, e identificarse con la imagen al mirarla. Jesus en de Ziel, en su conjunto, no es una reconstrucción de los

47 "A vacuum into which our identity of awareness is pulled... an empty shell that we inhabit which enables us to travel in another realm. We don't just observe the cartoon, we become it!" [Traducción del autor.] McCloud, Understanding Comics, 36.

48 "When we abstract an image through cartooning, we're not so much eliminating details as we are focusing on specific details. By stripping down an image to its essential "meaning" an artist can amplify that meaning in a way that realistic art can't." [Traducción del autor.] McCloud, Understanding Comics, 30. 
eventos bíblicos o de eventos contemporáneos a Luyken; es un compuesto de imágenes y textos que, por su inclinación a anclarse en nociones más generales de la vida espiritual cotidiana, trata de abarcar el viaje principal dentro y fuera del individuo. De esta manera representa los diversos motivos de un modo con el que la gran mayoría de los usuarios del libro podrían identificarse. Esto no significa que sea entonces algo meramente simbólico, en el sentido de que son sólo ideas sobre las que el usuario reflexiona o proyecta. Al contrario, lo que quiero argumentar es que su universalidad facilita que se conviertan en parte del repertorio visual que el individuo tiene a su disposición para entender y vivir su vida, entendida ésta como una comandada en, por y para Dios.

Este mismo aspecto de la representación del Alma puede aplicarse al corazón. Junto con las otras figuras y motivos de la imagen, además de los textos que la acompañan, la forma de "San Valentín" del corazón hace del mismo un contenedor, un vehículo, de los corazones y experiencias espirituales de todos. Hace del órgano un receptáculo para todos, en el cual el devoto puede proyectar su propio corazón. El ojo que posee en el Emblema XIV no altera esta función de representación, ya que este elemento en sí mismo se adhiere a este principio de utilizar motivos generales con los que se puede esperar que el lector se relacione, o que pueda desear tener. Los lectores deben querer estar vigilantes y espiritualmente despiertos. La imagen funciona entonces como una especie de espejo que se acomoda al usuario. Al no mostrar ningún detalle que haría del corazón un órgano particular perteneciente a un individuo particular, la imagen da al espectador espacio para percibir al corazón, su corazón, como humano y divino, como portador de emociones y del Espíritu, como el principal motor del cuerpo y la residencia del Alma y de Dios.

Jesús, por otro lado, es identificado como tal por el artista, a través del otorgamiento de atributos como el nimbo o las flores usadas como corona. Sin embargo, más allá de estos modestos elementos, no hay mucho en la representación de la figura de Jesús que se inspire en la iconografía cristiana anterior a 1678. No es cierto que Luyken nunca haya representado a 
Jesús siguiendo la tradición iconográfica: ciertamente hay ejemplos de su uso de iconografía cristológica en el momento que el objetivo era ilustrar acontecimientos de la narrativa bíblica. ${ }^{49}$ En estos casos, a través de la iconografía tradicional de Jesús, Luyken recrea un escenario de eventos pasados. Sin embargo, en Jesus en de Ziel el artista eligió inspirarse en la fórmula de los libros de emblemas católicos, como fue dicho en párrafos atrás. El Niño Jesús se utiliza para ilustrar la vida espiritual personal e interior, tal como se ha desarrollado, se está desarrollando y se desarrollará en el curso de la vida del creyente. La representación de la figura de Cristo como infante concuerda con la representación del Alma y el corazón: todos ellos sirven para dar una imagen genérica al usuario del libro, eliminando la distancia impuesta por los atributos iconográficos individuales o históricos.

En síntesis, esta representación visual del viaje que cada uno de los creyentes ha de llevar a cabo en su vida, en orden a cumplir la meta final, que es la unión con Dios, contribuye (proporciona acceso) a la forma en que lo divino va a ser experimentado por el individuo. Es una representación visual que, a través de la simplificación de los personajes, permite la identificación de una mayoría en cuanto a la forma de experimentar y ver a Dios. Los motivos empleados en la composición de la escena están, en su mayor parte, estilizados de manera que no transmiten necesariamente referencias concretas o específicas, sino que se refieren a conceptualizaciones visuales más generales de los objetos o figuras que representan, los cuales podemos adecuar a ser o hacer parte de nuestras herramientas para configurarnos a nosotros y a nuestra vivencia con Dios en nuestra cotidianidad. Esto puede decirse al menos de la manera en que el Alma, Jesús y el corazón han sido representados. El corazón y el Alma se convierten a través de sus estilizaciones, en vehículos o espejos adecuados para el corazón y el alma de todos. Esto, a su vez, incita a cobrar conciencia de que el viaje y los eventos tomados a lo largo del libro y dentro de las imágenes, pueden ser vistos como un viaje y un conjunto de eventos que cada creyente ha emprendido o experimentará.

49 Como sucede, por ejemplo, en los grabados para Het Nieuwe Testament ofte alle Boecken des Nieuwen Verbondts onses Heeren lesu Christi (1681). 
El Alma, el corazón y Jesús no son ni la verdadera Alma, ni el corazón y mucho menos Jesús, sino marcas visuales que proveen información de cómo moldear y experimentar la noción misma de Alma, corazón y Jesús. Al mismo tiempo, el texto del Emblema XIV también transmite información sobre la realidad y la forma visual que representa. Juntos consiguen suministrar esa información y proporcionar ese acceso de manera que se recibe el conocimiento de un modo en particular. ${ }^{50}$ En un libro emblemático como el de Luyken, la imagen, como parte de un mensaje, puede dar acceso a una serie de objetivos, ideas, formas y sensaciones que son a su vez propuestas en forma verbal por el poeta. La imagen entonces, junto con el texto, se convierten en herramientas que intentan imprimir en el creyente una forma de entender su vida espiritual, y el papel del corazón en ella.

La poesía, por supuesto, puede ser empleada de manera similar, es decir, como una herramienta para el aprendizaje, que utiliza patrones en la rima y repetición para reforzar su propósito pedagógico. En la primera mención del corazón en el poema del Emblema XIV, por ejemplo, la idea central del poema se ubica en cuatro versos en los que las rimas actúan como una especie de marco para la imagen:

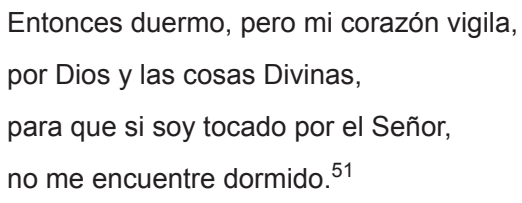

Así como en esta primera estrofa del poema aprendemos precisamente lo que miramos en la imagen, también podríamos especular sobre cómo la contemplación de la imagen podría ocurrir antes de la lectura del texto, y así informar al lector de la comprensión del poema. Es concebible que sólo por

50 Cfr. Gibson, The Ecological Approach...

51 "Soo slaep ick, maer mijn herte waeckt, / Op Godt en Goddelijcke dingen, / Op dat als my den Heer genaeckt, / Hy my niet vindt in sluymeringen". [Traducción del autor.] Luyken, Jesus en de ziel, 64. 
el hecho de mirar la imagen se activen el poema, los versos bíblicos y los elementos de la reflexión que lo acompañan. Como herramienta, la imagen añade entonces a su gama de ofrecimientos la de servir como un dispositivo para recordar o acceder a la información. Esto puede ocurrir de múltiples maneras, y la red de asociaciones simultáneas no tiene por qué ser activada necesariamente por la imagen. Puede suceder con el Emblema XIV, por ejemplo, que si yo o alguien de mi audiencia recita o incluso sólo alude al texto del Cantar de los Cantares 5:2, el grabado de Luyken forme parte de mis recursos visuales, que inmediatamente serán puestos en juego para mediar la Palabra de Dios y mi comprensión o consumo de la misma.

Hacemos de algunas imágenes portales a mundos de acciones, emociones, causas y consecuencias. Las imágenes son objetos que forman parte de nuestro entorno, cooperan para moldear nuestro comportamiento y sistema social. Nuestras vidas están mediadas por ellas y, por este motivo, son herramientas. La imagen es un vehículo de elementos propios o al menos adscritos a nosotros y, por lo tanto, es capaz de desarrollar parte de lo que entendemos como realidad. Las imágenes son, consciente o inconscientemente para nosotros, herramientas para ver, modos referenciales en cuanto a cómo nuestra sensibilidad interactúa con el entorno. ${ }^{52}$ En otras palabras, debido a las condiciones en que realizamos el acto de mirar, las imágenes se convierten en extensiones de nuestro ser, las utilizamos para comprender, experimentar o comportarnos en relación con lo que nos rodea; y éstas afectan y modifican nuestra experiencia de vida.

Ahora bien, una vez entendidas como herramientas que nos proveen extensión, podemos enfocarnos en la idea de que estos dispositivos también proporcionan extensión en cuanto a lo religioso, es decir: las imágenes forman parte de las prácticas de mediación religiosa. Las imágenes proporcionan un espacio físico, una presencia en nuestra realidad sensorial a lo divino. Ésta no es una acción propia sólo de la imagen, sino que está con-

52 Noë, Strange Tools, 52. 
dicionada a un entorno específico, a una red enmarañada por una serie de condiciones y reglas para la interacción donde la imagen está involucrada con la práctica religiosa.

Luyken plantea en Jesus en de Ziel el principio general de que hay una manera de ver y de comportarse con el mundo y con nosotros mismos que sólo es posible si aceptamos a Dios en nuestros corazones, y si lo hacemos de forma constante. La presencia física de Dios proporcionada por el libro media la comprensión por parte del creyente de que Dios está en su interior, y que a través de él su entorno y sus vivencias tienen una connotación divina, postura que continuará hasta que el usuario alcance la muerte y pueda unirse al Reino de los Cielos. Esto es realizado a través de una narrativa expuesta visual y textualmente de forma simultánea por Luyken, ayudada (o respaldada) por la misma Palabra de Dios que acompaña en todo momento tanto los poemas como los grabados del autor. Este tema, de hecho, subyace en el resto de su obra literaria emblemática. Como señala Vekeman, Jesus en de Ziel organiza en una etapa temprana un componente significativo del sistema de pensamiento que Luyken continuará presentando a lo largo de su trabajo devocional, a saber: el elemento del nuevo nacimiento y el posterior retorno del creyente a mirar las realidades sensoriales, pero ahora como una criatura nacida de nuevo. ${ }^{53}$

53 Vekeman, “'Jezus en de ziel'," 185. Aunque el corazón no aparece como motivo visual en toda su obra, este argumento visual y textual permanecerá más o menos igual en todo el trabajo emblemático de Luyken. Pueden mencionarse como ejemplos que provienen de la mano de Luyken donde se incluye el motivo visual del corazón: Beschouwing der Wereld (1708), De Zedelyke en Stichtelyke Gezangen (1709) y De Onwaardige Wereld (1710), los tres de la autoría de Luyken. Además, el artista hizo numerosos grabados para diversas publicaciones religiosas, donde aparece el motivo visual del corazón, y de las cuales se podría argumentar que se expresan intenciones similares a las que observamos en su obra personal. Estas publicaciones son: Goddelyke Liefde-Vlammen (1681), publicado y algunos casos atribuido a Johannes Boekholt; tres libros de Willem Deurhoff: Voorleeringen van de Heilige Godgeleerdheid (1687), Bespiegeling Van de Heilige Godgeleerdheid (1687), y Grondvesten van de Christelyke Godsdienst (1690). Por otro lado, encontramos también el corazón en De Theologieze Werken, Behlsende in twee Dele d'onderwysinge van de Christelyke Religie, en den Zeden-Spiegel der Deguden (1678) de Stephanus Curcellaeus; el Waereld vol Stryd, of Algemeen Worstelperk van 't rampspoedig menschom (1706) de Herkules Bouman; y finalmente, el Sedige Bedenckingen (1702), de un autor que no se ha podido identificar hasta el momento. Además, se pueden encontrar ejemplos explícitos, aunque sin que se considere 
EI Emblema XIV es, por lo tanto, una herramienta de acceso que se sirve de la complementariedad entre palabra e imagen, característica de los emblemas, para que el creyente entienda (y experimente) su propia vida y su cuerpo, dentro del peregrinaje divino propuesto que ha de hacerse, acompañado de Jesús, para unirse a Dios. El lector de Jesus en de Ziel comprende que el Alma, su propia alma, emprende un viaje. Las imágenes y palabras dan forma a un viaje que implica el rechazo de la carne y del mundo, el nuevo nacimiento y el alimento de una nueva condición como ser humano que ha permitido a Dios, a través de Jesús, habitar en su interior. El Emblema XIV, tanto en términos visuales como textuales, muestra al corazón como agente activo y pasivo, con lo que mantiene la idea de que es en tal órgano donde reside el verdadero yo y que, por la revelación de Dios a nosotros y la apertura de nuestros divinos ojos espirituales, es capaz de entender y ver muchas cosas que la carne, el mundo y el mal mantienen veladas. En el corazón vive la criatura que ha nacido de nuevo, que necesita constantemente morir en Cristo, renacer y comportarse acorde a ello, sabiendo que, aunque se ha vuelto (una vez más) internamente divino - o consciente de su naturaleza divina primordial—, el creyente necesita constantemente progresar (batallar), porque hasta su muerte estará unido al Viejo Adán. En el emblema, el corazón no es meramente una metáfora o alegoría para referirse a diversas ideas, sino que representa lo que realmente es en la vida del ser humano. La imagen del corazón sirve, por lo tanto, no sólo para hacer visible lo invisible (a saber, el Alma), sino también para indicar que hay un lugar real y corporal en el que habita lo invisible, y que ahí mismo es donde habita Dios.

\section{Bibliografía}

Barnard, Malcom. Graphic Design as Communication. Londres y Nueva York: Routledge, 2005.

Daly, M. Peter. “Emblems: An Introduction”. En Peter M. Daly (ed.). Companion to Emblem Studies. Nueva York: AMS Press, Inc., 2008, 1-24.

necesaria una representación visual del corazón, en Voncken der liefde Jesu (1687), Het menselyk bedryf (1694), Het leerzaam huisraad (1711) y Des Menschen begin, midden en einde (1712), todos éstos de la autoría de Luyken. 
Decker, John R. "'Practical Devotion.' Apotropaism and the Protection of the Soul”. En Celeste Brusati, Karl A. E. Enenkel y Walter S. Melion (eds.). The Authority of the Word: Reflecting on Image and Text in Northern Europe, 1400-1700. Leiden y Boston: Brill, 2012, 357-383.

Decker, John R. The Technology of Salvation and the Art of Geertgen tot Sint Jans. Farnham: Ashgate, 2009.

Den Hollander, August, Mirjam van Veen, Anna Voolstra y Alex Noord (eds.). Religious Minorities and Cultural Diversity in the Dutch Republic: Studies Presented to Piet Visser on the Occasion of his $65^{\text {th }}$ Birthday. Boston y Leiden: Brill, 2014.

Der Weduwen, Arthur y Andrew Pettegree. The Bookshop of the World: Making and Trading Books in the Dutch Golden Age. New Haven y Londres: Yale University Press, 2019.

Der Weduwen, Arthur y Andrew Pettegree. The Dutch Republic and the Birth of Modern Advertising. Boston y Leiden: Brill, 2020.

Dietz, Feike. Literaire levensaders: Internationale uitwisseling van word, beeld en religie in de Republiek. Hilversum: Verloren, 2012.

Dietz, Feike y Els Stronks. "German Religious Emblems as Stimuli of Visual Culture in the Dutch Republic". Church History and Religious Culture 91 (2011): 349-375.

Gibson, James J. The Ecological Approach to Visual Perception. Boston: Houghton Mifflin Company, 1979.

Kress, Gunther y Theo van Leeuwen. Reading Images: The Grammar of Visual Design. Londres y Nueva York: Routledge, 2006.

Lerner, Robert E. "The Image of Mixed Liquids in Late Medieval Mystical Thought". Church History 40, núm. 4 (diciembre de 1971): 397-411.

Lewalski, Barbara K. Protestant Poetics and the Seventeenth-Century Religious Lyric. Princeton: Princeton University Press, 1985.

Luyken, Jan. Jesus en de ziel: Een geestelijck spiegel voor't gemoed. Ámsterdam: Pieter Arentsz, 1678. Signature (OK 65-1721), Identifier (OCLC: 63795630). Universiteitsbibliotheek Amsterdam.

McCloud, Scott. Understanding Comics. Nueva York: Harper Perennial, 1994.

Meyer, Birgit. "Mediating Absence - Effecting Spiritual Presence: Pictures and the Christian Imagination". Social Research 78, núm. 4 (invierno de 2011): 1029-1056. 
Meyer, Birgit. "Picturing the Invisible: Visual Culture and the Study of Religion". Method and Theory in the Study of Religion 27, núm. 4/5 (2015): 333-360.

Noë, Alva. Strange Tools: Art and Human Nature. Nueva York: Hill and Wang, 2015.

Noë, Alva. Varieties of Presence. Cambridge: Harvard University Press, 2012.

Orsi, Robert A. Between Heaven and Earth: The Religious Worlds People Make and the Scholars who Study Them. Princeton y Oxford: Princeton University Press, 2005.

Orsi, Robert A. History and Presence. Cambridge: The Belknap Press of Harvard University Press, 2016.

Panofksy, Erwin. Studies in Iconology: Humanistic Themes in the Art of the Renaissance. Colorado: Icon Editions, 1972.

Po-Chia Hsia, R. y Henk van Nierop (eds.). Calvinism and Religious Toleration in the Dutch Golden Age. Cambridge: Cambridge University Press, 2002.

Porteman, Karel y Mieke B. Smits-Veldt. Een nieuw vaderland voor de muzen: Geschiedenis van de Nederlandse literatuur 1560-1700. Ámsterdam: Bert Bakker, 2008.

Schorsch, Anita. "Emblematic and Allegorical Images of Body and Soul". En Peter M. Daly y Daniel S. Russel (eds.). Emblematic Perceptions: Essays in Honor of William S. Heckscher on the Occasion of His Ninetieth Birthday. Baden-Baden: V. Koerner, 1997: 159-188.

Siegert, Bernhard. Cultural Techniques: Grids, Filters, Doors, and Other Articulations of the Real. Nueva York: Fordham University Press, 2015.

Stronks, Els. "Dutch Religious Love Emblems: Reflections of Faith and Toleration in the Later $17^{\text {th }}$ Century". Literature and Theology 23, núm. 2 (junio de 2009): 142-164.

Stronks, Els. Negotiating Differences: Word, Image and Religion in the Dutch Republic. Leiden: Brill, 2011.

Stronks, Els. "Working the Senses with Words: The Act of Religious Reading in the Dutch Republic". En Celeste Bursati, Karl A.E. Enenkel y Walter S Melion (eds.). The Authority of the Word: Reflecting on Image and Text in Northern Europe, 1400-1700. Leiden y Boston: Brill, 2012, 667-702. 
Vekeman, Herman W. J. 'JJezus en de ziel' Jan Luyken tussen essentie en existentie". Tijdschrift voor Nederlandse Taal- en Letterkunde 95 (1979): 177-203.

Veld, Henk van 't. Jan Luyken (1649-1712): Leven en werk in woord en beeld. Apeldoorn: Uitgeverij De Banier, 2017.

Vernant, Jean-P. Myth and Thought among the Greeks. Londres y Boston: Routledge \& Kegan Paul, 1983.

Westerweel, Bart. "On the European Dimension of Dutch Emblem Production". En Alison Adams y Marleen van der Wij (eds.). Emblems of the Low Countries: A Book Historical Perspective. Glasgow: Glasgow Emblem Studies (Universidad de Glasgow), 2003, 1-16.

\section{Mauricio Oviedo Salazar}

Estudiante de doctorado en la Facultad de Teología y Estudios Religiosos de la Universidad de Groninga (Rijksuniversiteit Groningen), donde se encuentra realizando la tesis "A Perennial Heart: The Organ as a Catholic and Protestant Visual Motif in the Culture and Devotion of New Spain and the Netherlands in the Seventeenth and Eighteenth Centuries". ${ }^{54}$ Cuenta con estudios de Maestría en Estudios Religiosos con énfasis en Esoterismo Occidental, por la Universidad de Ámsterdam. Realizó sus estudios de pregrado en Historia del Arte en la Universidad de Costa Rica. En su carrera académica ha publicado varios artículos y participado en distintas conferencias, con temas dirigidos a historiografía del arte, arte religioso, astrología y arte costarricense.

\footnotetext{
54 Un corazón perenne: el órgano como motivo visual católico y protestante en la cultura y la devoción de la Nueva España y los Países Bajos en los siglos XVII y XVIII.
} 